\title{
Influence of lipid type on gastrointestinal fate of oil-in-water emulsions: In vitro digestion study
}

\section{Ruojie Zhang1,2, Zipei Zhang1,2, Hui Zhang1, Eric Andrew Decker $^{2,3}$, and David Julian McClements ${ }^{2,31}$}

${ }^{1}$ School of Food Science and Technology, Jiangnan University, 1800 Lihu Avenue, Wuxi 214122, China

${ }^{2}$ Department of Food Science, University of Massachusetts Amherst, Amherst, MA 01003, USA

${ }^{3}$ Department of Biochemistry, Faculty of Science, King Abdulaziz University, P. O. Box 80203 Jeddah 21589 Saudi Arabia

Journal: Food Research International

Submitted: April 2014

1 David Julian McClements, Department of Food Science, University of Massachusetts Amherst, Amherst, MA 01003, USA. 413545 1019; mcclements@foodsci.umass.edu 


\begin{abstract}
The potential gastrointestinal fate of oil-in-water emulsions containing lipid phases from different sources was examined: vegetable oils (corn, olive, sunflower, and canola oil); marine oils (fish and krill oil); flavor oils (orange and lemon oil); and, medium chain triglycerides (MCT). The lowest rates and extents of lipid digestion were observed for emulsified flavor oil, followed by emulsified krill oil. There was no appreciable difference between the final amounts of free fatty acids released for emulsified digestible oils. Differences in the digestibility of emulsions prepared using different oils were attributed to differences in their compositions, e.g., fatty acid chain length and unsaturation. The particle size distribution, particle charge, microstructure, and macroscopic appearance of the emulsions during passage through the simulated GIT depended on oil type. The results of this study may facilitate the design of functional foods that control the digestion and absorption of triglycerides, as well as the bioaccessibility of hydrophobic bioactives.
\end{abstract}

Key words: emulsion; oil type; gastrointestinal; lipid digestion; free fatty acids 


\section{Introduction}

Lipids play an important role in the human diet, providing energy, essential nutrients, and bioactive components. Digestible lipids derived from different sources have different triacylglycerol compositions, varying in the type, number, and location of the fatty acids. Fatty acids vary in their chain length and unsaturation, which leads to appreciable differences in their physical, chemical, and nutritional properties. Typically, lipids derived from plants contain high levels of unsaturated fatty acids (such as oleic, linoleic, and linolenic acid), whereas those derived from animals contain high levels of saturated fatty acids (such as palmitic and stearic acid) (Akoh \& Min, 2008). In addition, lipids derived from marine sources (such as fish and krill oils) tend to have high levels of $\omega-3$ polyunsaturated fatty acids (such as docosahexaenoic acid (DHA) and eicosapentaenoic acid (EPA)) (Akoh \& Min, 2008). The initial type of the lipid phase within an ingested food may impact its subsequent digestion and absorption (Porter, Trevaskis, \& Charman, 2007), which can be attributed to differences in fatty acid composition (McClements, Decker, \& Park, 2008; Singh, Ye, \& Horne, 2009).

An improved understanding of the impact of oil type on the gastrointestinal fate of dietary lipids would enable the food industry to design foods to modulate lipid digestion and absorption within the human gastrointestinal tract (GIT). In addition, studies have shown that the bioaccessibility of encapsulated hydrophobic bioactives depends on the gastrointestinal fate of the lipid phase surrounding them (Gleize et al., 2013; Qian, Decker, Xiao, \& McClements, 2012; Salvia-Trujillo, Qian, Martin-Belloso, \& McClements, 2013). In particular, the bioaccessibility of hydrophobic bioactives increases appreciably when they are encapsulated within emulsion-based systems fabricated from long chain triglycerides (Qian et al., 2012; Yang \& McClements, 2013) or when they are mixed with foods containing long chain triglycerides (Chitchumroonchokchai, Schwartz, \& Failla, 2004; Hedren, Diaz, \& Svanberg, 2002; Hedrén, Mulokozi, \& Svanberg, 2002; Huo, Ferruzzi, Schwartz, \& 
Failla, 2007). The origin of this effect has been attributed to the fact that highly hydrophobic bioactives must be solubilized and transported within mixed micelles before they can be delivered to epithelium cells and absorbed (Borel, 2003; Colle, Van Buggenhout, Lemmens, Van Loey, \& Hendrickx, 2012). The co-ingestion of hydrophobic bioactives with lipids capable of forming mixed micelles is therefore thought to be critical for the absorption of many hydrophobic bioactives. Different types of fatty acids may form mixed micelles with different solubilization capacities, and therefore oil type may have a pronounced influence on bioaccessibility (Nidhi \& Baskaran, 2011).

The digestion and absorption of dietary lipids is a complex process involving numerous physicochemical and biochemical events throughout the gastrointestinal tract (Johnson, 2013; McClements, Decker, \& Park, 2007; Singh et al., 2009). In the mouth, an ingested food is mixed with saliva, undergoes temperature and $\mathrm{pH}$ changes, and is subjected to mechanical forces, which may alter the structural organization, physical state, and interfacial properties of the lipid phase. In the stomach, the lipids are mixed with highly acidic gastric fluids that contain minerals, biopolymers, surface active lipids, and enzymes. The lipid phase may undergo further changes in structural organization due to droplet fragmentation and aggregation processes, as well as changes in the nature and composition of the lipid-water interface. In the small intestine, lipids are mixed with alkaline intestinal fluids that contain pancreatic lipase, colipase, proteases, bile salts, and phospholipids. The bile salts and phospholipids may adsorb to the surfaces of the lipid droplets and displace other surface active materials. The lipase/colipase complex may then adsorb to the lipid-water interface and convert the emulsified triacylglycerols into free fatty acids and monoacylglycerols. These lipid digestion products then mixed with bile salts and phospholipids to form the mixed micelle phase. An improved understanding of changes in the physicochemical and biochemical properties of different types of lipid 
in the gastrointestinal tract may facilitate the rational design of functional foods, e.g., to induce satiety or to control the release and uptake of bioactives.

In this study, oil-in-water emulsions were prepared using nine food oils from different sources: four vegetable oils (corn, olive sunflower, and canola oil); two marine oils (fish and krill oil); two flavor oils (orange and lemon oil); and one medium chain triglyceride (MCT) oil. These oils were selected because they are commonly used to prepare emulsions in the food industry and because they had different lipid phase compositions. We examined the influence of oil type on the gastrointestinal fate of oil-in-water emulsions using a simulated GIT that includes the mouth, stomach, and small intestine phases. A number of previous researchers have also examined the influence of oil type on lipid digestion of oil-in-water emulsions using simulated GIT models. Hur and co-workers reported that the total amount of free fatty acids released from emulsions after lipase digestion decreased in the following order: lard $>$ olive oil $>$ corn oil $\approx$ soybean oil (Hur, Joo, Lim, Decker, \& McClements, 2011), whereas Zhu and co-workers reported that it decreased in the following order for the oils they studied: milk fat > soya oil > fish oil (Zhu, Ye, Verrier, \& Singh, 2013). Interestingly, these authors also reported that there were appreciable differences in the digestion and release rate of different types of free fatty acids: short chain > long chain; saturated > unsaturated. In the current study, we studied the potential gastrointestinal fate and lipid digestion of a wide range of different food oils using standardized simulated gastrointestinal conditions, so that comparisons could be made between different lipid sources under similar conditions.

The results of this study should facilitate the rational design of functional foods that may control lipid digestion or improve the bioaccessibility profile of hydrophobic bioactives.

\section{Materials and methods}




\subsection{Materials}

Whey protein isolate (WPI) was obtained from Davisco Foods International Inc. (Le Sueur, MN). As stated by the manufacturer, the protein content was 97.6\% (dry basis). Medium chain triglyceride (MCT) oil was obtained from Coletica (Northport, NY). Corn oil was purchased from a commercial food supplier (Mazola, ACH Food Companies, Memphis, TN). The manufacturer reported that the saturated, monounsaturated, and polyunsaturated fat content of this product were approximately 14, 29, and 57\%, respectively. Olive oil was purchased from Salov North America Corp. (Lyndhurst, NJ). The manufacturer reported that the saturated, monounsaturated, and polyunsaturated fat content of this product were approximately 14,14 , and $72 \%$, respectively. Sunflower oil was purchased from World Brands, Inc (Skokie, IL). The manufacturer reported that the saturated, monounsaturated, and polyunsaturated fat content of this product were approximately 11, 29, and 60\%, respectively. Canola oil was purchased from Foodhold U.S.A., LLC (Landover, MD). The manufacturer reported that the saturated, monounsaturated, and polyunsaturated fat content of this product were approximately 11, 29, and $60 \%$, respectively. Fish oil was purchased from DSM Nutritional Products Ltd. (Basel, Switzerland). The manufacturer reported that DHA, EPA and Omega 3 levels in this product were 14.8, 10.1, and 31.2\%, respectively. Krill oil (Lot\# KR-00321) was obtained from Enzymotec Ltd. (Baruch, Israel). The manufacturer reported that the phospholipids, DHA, EPA and Omega 3 content were $41,6,11$ and $21 \%$, respectively. Lemon oil ( $3 \times$ fold) was purchased from Citrus \& Allied Essences (Lake Success, NY). Orange oil $(10 \times$ fold, item\# 49024) was obtained from the Chemistry Store (Cayce, SC). Mucin from porcine stomach, pepsin from porcine gastric mucosa (250 units/mg), porcine lipase (100-400 units/mg), and porcine bile extract were purchased from Sigma-Aldrich (Sigma Chemical Co., St. Louis, MO). All other chemicals used in this paper were purchased from either Sigma-Aldrich (Sigma Chemical Co., St. Louis, MO) or Fisher Scientific (Pittsburgh, PA). All solvents and reagents were of analytical grade. Double distilled 
water from a water purification system (Nanopure Infinity, Barnstaeas International, Dubuque, IA) was used for preparation of all solutions.

\subsection{Emulsion preparation}

Stock emulsions were prepared by homogenizing $10 \mathrm{wt} \%$ oil phase (various oils) with $90 \mathrm{wt} \%$ aqueous phase $(1.0 \mathrm{wt} \%$ whey protein isolate, $5 \mathrm{mM}$ phosphate buffer, $\mathrm{pH}$ 7.0). Initially, a coarse emulsion was prepared using a high-speed blender for 2 min (M133/1281-0, Biospec Products, Inc., ESGC, Switzerland), and then this emulsion was passed through a high pressure homogenizer (M110Y, Microfluidics, Newton, MA) with a $75 \mu \mathrm{m}$ interaction chamber (F20Y) at a pressure of 11,000 psi for 3 passes to create a fine emulsion.

\subsection{In vitro digestion model}

Emulsions were passed through a GIT model that simulated the mouth, stomach, and small intestine. This method has been described in detail in our previous study (Zhang, Zhang, Zhang, Decker, \& McClements, 2015), and so is only briefly summarized below.

Initial system: $20 \mathrm{~mL}$ emulsions containing $2 \mathrm{wt} \%$ oil were placed into a glass beaker in an incubated shaker (Innova Incubator Shaker, Model 4080, New Brunswick Scientific, New Jersey, USA) at $37^{\circ} \mathrm{C}$.

Mouth phase: $20 \mathrm{~mL}$ of simulated saliva fluid (SSF) containing $0.03 \mathrm{~g} / \mathrm{mL}$ mucin were preheated to $37{ }^{\circ} \mathrm{C}$ and then mixed with the initial emulsions. After being adjusted to $\mathrm{pH} 6.8$, the mixture was incubated in the incubator shaker for $10 \mathrm{~min}$ at 37 ${ }^{\circ} \mathrm{C}$ to mimic agitation in the mouth.

Stomach phase: $20 \mathrm{~mL}$ of the "bolus" sample resulting from the mouth phase was mixed with $20 \mathrm{~mL}$ of simulated gastric fluid containing $0.0032 \mathrm{~g} / \mathrm{mL}$ pepsin preheated to $37{ }^{\circ} \mathrm{C}$ and then the $\mathrm{pH}$ was adjusted to 2.5 . This mixture was incubated in the incubator shaker for $2 \mathrm{~h}$ at $37^{\circ} \mathrm{C}$ to mimic stomach conditions.

Small intestine phase: $30 \mathrm{~g}$ of "chyme" sample from the stomach phase was 
placed into a $100 \mathrm{~mL}$ glass beaker that was placed into a water bath at $37^{\circ} \mathrm{C}$ and then adjusted to $\mathrm{pH}$ 7.00. $1.5 \mathrm{~mL}$ of simulated intestinal fluid was added to the reaction vessel, followed by $3.5 \mathrm{~mL}$ of bile salt solution with constant stirring. The $\mathrm{pH}$ of the reaction system was adjusted back to $7.00 .2 .5 \mathrm{~mL}$ of lipase solution was then added to the sample and an automatic titration unit (Metrohm,USA Inc.) was used to monitor the $\mathrm{pH}$ and maintain it at $\mathrm{pH} 7.0$ by titrating $0.1 \mathrm{mM} \mathrm{NaOH}$ solution into the reaction vessel for $2 \mathrm{~h}$ at $37^{\circ} \mathrm{C}$. The amount of free fatty acids released was calculated from the titration curves as described previously ( $\mathrm{Li} \&$ McClements, 2010). The release of free fatty acids from digestible oil emulsions was calculated by subtracting the FFA concentration determined at each time point for the indigestible oil (orange oil) emulsion from the FFA concentration determined for the emulsions containing digestible oils (Rao, Decker, Xiao, \& McClements, 2013).

\subsection{Determination of particle characterisation}

The particle size distribution and $\zeta$-potential of the samples were measured using a static light scattering device (Mastersizer 2000, Malvern Instruments Ltd., Malvern, Worcestershire, UK) and an electrophoresis instrument (Zetasizer Nano ZS series, Malvern Instruments Ltd. Worcestershire, UK), respectively. The $\zeta$-potential was calculated from the electrophoretic mobility measurements using the Smoluchowski approximation. Initial, mouth, and small intestine samples were diluted by phosphate buffer (5 mM, pH 7.0) and stomach samples were diluted with acidified water ( $\mathrm{pH} 2.5)$ to avoid multiple scattering effects. The refractive index of the oil phase used in the calculations depended on oil type: 1.445 for MCT; 1.472 for corn oil; 1.469 for olive oil; 1.472 for sunflower oil; 1.473 for canola oil; 1.481 for marine oils; 1.4715 for orange oil; and 1.476 for lemon oil (Farag, Mahmoud, \& Basuny, 2007; Komaiko \& McClements, 2015; Qiu, Zhao, Decker, \& McClements, 2015; Yang \& McClements, 2013). The average particle sizes are reported as the surface-weighted mean diameter $\left(\mathrm{d}_{32}\right)$.

The microstructures of all samples were observed using confocal scanning laser 
microscopy with a $60 \times$ oil immersion objective lens (Nikon D-Eclipse C1 80i, Nikon, Melville, NY, US.). Before analysis $2 \mathrm{~mL}$ samples were mixed with $0.1 \mathrm{~mL}$ Nile Red solution $(1 \mathrm{mg} / \mathrm{mL}$ ethanol) to dye the oil phase, and $0.1 \mathrm{~mL}$ FITC solution (10 $\mathrm{mg} / \mathrm{mL}$ dimethyl sulphoxide) to dye the protein. The excitation and emission spectrum for Nile red were $543 \mathrm{~nm}$ and $605 \mathrm{~nm}$, respectively, while for FITC were 488nm and $515 \mathrm{~nm}$, respectively. An aliquot of sample was placed on a microscope slide, covered by a cover slip, and then microstructure images were acquired using image analysis software (NIS-Elements, Nikon, Melville, NY).

\subsection{Statistical analysis}

All experiments were performed on at least two freshly prepared samples. The results are reported as averages and standard deviations calculated from these measurements using a statistical software package (SPSS).

\section{Results and Discussions}

\subsection{Influence of oil type on emulsion physical stability in digestion model}

In this section, the physical stabilities of emulsions prepared from the nine different oils were examined as they passed through the simulated GIT. The mean particle size, particle size distribution, microstructure, and macroscopic appearance of the emulsions were determined at each stage of the GIT model (Figures 1 to 4). As the oils in similar classes showed similar behavior, we only report the results for corn oil as representative of all the vegetable oils, and orange oil as representative of both favor oils.

The mean particle diameter $\left(d_{32}\right)$ was relatively small and fairly similar $(0.12$ to $0.18 \mu \mathrm{m})$ for all the initial emulsions containing triacylglycerol oils, but was appreciably bigger for the flavor oils $(0.59 \mu \mathrm{m})$ (Figure 1). The particle size distribution results also showed that there was a population of relatively large droplets in the orange oil emulsions (Figure 2). A likely explanation for this phenomenon is Ostwald ripening occurring after emulsion formation, i.e., droplet growth due to the 
diffusion of flavor oil molecules from the small to the large droplets (Chang \& McClements, 2014). It has previously been reported that Ostwald ripening occurs rapidly in oil-in-water emulsions containing flavor oils because of their relatively high water solubility (McClements, Henson, Popplewell, Decker, \& Jun Choi, 2012; Rao \& McClements, 2012). Initially, all the oil droplets appeared to be uniformly distributed throughout the emulsions as observed by confocal microscopy (Figure 3), which suggests that droplet flocculation did not occur.

After passing through the mouth phase, the particle size distributions of all the emulsions became bimodal, with a corresponding increase in mean particle diameter $\left(\mathrm{d}_{32}\right)$. The confocal microscopy images also showed that extensive droplet aggregation occurred under simulated mouth conditions. Previous studies suggest that droplet aggregation may be caused by either bridging or depletion flocculation induced by the presence of mucin in the simulated saliva (Sarkar, Goh, \& Singh, 2009; Vingerhoeds, Blijdenstein, Zoet, \& van Aken, 2005), which is also in agreement with our previous study (Salvia-Trujillo, Qian, Martín-Belloso, \& McClements, 2013). Bridging flocculation occurs due to the binding of mucin molecules to the surfaces of two or more oil droplets, whereas depletion flocculation occurs due to the increase in the osmotic attractive forces between the droplets generated by non-adsorbed mucin molecules.

After passing through the stomach phase, all the emulsions exhibited a large increase in mean particle diameter as measured by light scattering (Figure 1) and extensive droplet aggregation as detected by confocal microscopy (Figure 4). This result is in agreement with previous studies that have reported that protein-stabilized emulsions are prone to aggregation under gastric conditions due to hydrolysis of adsorbed proteins, weakening of electrostatic repulsion, and depletion or bridging flocculation induced by mucin (Singh et al., 2009; Zhang et al., 2015). The macroscopic appearance of the krill oil emulsions was quite different from the other 
emulsions after exposure to the simulated stomach stage (Figure 5). The other emulsions separated into a white cream layer on the top (presumably consisting of oil droplets) and a thin white sediment layer at the bottom (presumably consisting of undigested proteins and other substances). In contrast, the krill oil emulsions only formed a thick brownish sediment layer at the bottom. In addition, the microstructures of the krill oil emulsions after exposure to the stomach were also different from the other emulsions (Figure 3). The emulsions containing MCT or corn oil appeared to contain relatively large oil droplets, suggesting that coalescence had occurred. These large oil droplets will be highly susceptible to creaming, which accounts for the formation of the white layer at the top of the test tubes. In contrast, the emulsions containing krill oil appeared to contain large nebulous clumps after exposure to the stomach stage. Krill oil is known to contain a relatively high proportion of phospholipids (41\% according to the manufacturer), which are more dense than triacylglycerols. Consequently, these large clumps may have been denser than water and sank to the bottom of the test tubes. These results clearly show that phospholipid-rich krill oil behaves quite differently from other triacylglycerol-rich oils under simulated stomach conditions, which may have important implications for its gastrointestinal fate. Indeed, in vivo studies have reported higher bioavailability of omega-3 fatty acids when delivered as krill oil rather than as fish oil, which was partly attributed to the fact that the polyunsaturated fatty acids were part of phospholipids in krill oil (Kohler, Sarkkinen, Tapola, Niskanen, \& Bruheim, 2015; Schuchardt et al., 2011). Conversely, other in vivo studies have reported a higher bioavailability of polyunsaturated fats from fish oils than from krill oil (Tou, Altman, Gigliotti, Benedito, \& Cordonier, 2011). Further research is required to better understand the behavior of krill oil within the GIT, and how this may be used to control lipid digestion and bioactive release.

After passing through the small intestinal stage, all the emulsions contained relatively large particles as detected by both light scattering and confocal microscopy 
methods. It is difficult to ascertain the precise nature of these particles since there may be many different types present, including undigested lipid droplets, undigested protein aggregates, micelles, vesicles, and insoluble calcium salts. In general, the particles present in the samples containing vegetable or marine oil were smaller than those in the samples containing MCT or flavor oil. Other studies have reported that MCT emulsions lead to the formation of larger particles after small intestine digestion than corn oil emulsions (Qian et al., 2012; Yang \& McClements, 2013). These large particles may be the result of the formation of larger vesicles after ingestion of MCT (since all of the lipid phase was fully digested - see later). The large particles observed in the flavor oil emulsions after small intestine digestion $(\approx 19 \mu \mathrm{m}$ for both orange and lemon oil) may have been because the oil phase was not digested. Instead, extensive droplet coalescence may have occurred in these emulsions once the initial protein emulsifier layer was digested and displaced in the small intestine (Qian et al., 2012).

\subsection{Influence of oil type on charge characterization}

In this section, changes in the electrical characteristics of the particles in the emulsions were measured as they passed through the different stages of the GIT model to provide information about alterations in interfacial properties (Figure 5).

All the initial emulsions contained emulsion droplets that had a highly negative charge (from -46 to $-67 \mathrm{mV}$ ). Nevertheless, there were some differences in the electrical characteristics of oil droplets prepared using different oil types. The strong negative charge on all the emulsions can mainly be attributed to the presence of the whey protein molecules at the droplet surfaces. Whey protein isolate (WPI) is above its isoelectric point $(\mathrm{pI}=5.1)$ at the initial solution conditions $(\mathrm{pH} 7)$, and therefore has a negative charge. The reason for the different magnitude of the electric charges on different emulsion droplets may be due to impurities present within the lipid phase. For example, anionic or cationic impurities in the oil phase could adsorb to the 
oil-water interface and contribute to the overall interfacial charge, e.g. free fatty acids, phospholipids, or mineral ions.

After passing through the mouth phase, there was an appreciable decrease in the magnitude of the negative charge on all of the oil droplets. This reduction may be due to electrostatic screening by mineral ions present within the simulated saliva (Israelachvili, 2011), or it may have been due to interactions of the mucin molecules with the oil droplet surfaces. There was a further decrease in the magnitude of the electrical charge when the emulsions were subjected to simulated stomach conditions. The simulated gastric fluids have a low $\mathrm{pH}$ and high ionic strength, which will result in a change in the electrical properties of the droplets. Electrostatic screening by mineral counter-ions will reduce the magnitude of the $\zeta$-potential on droplets. The relatively low $\mathrm{pH}$ will mean that the whey proteins in the samples should become negatively charged because they are below their isoelectric point. The fact that the droplets were slightly negatively under gastric conditions suggests that they were not only coated by whey proteins. It is likely that some of the proteins may have been digested and displaced, and that some of the mucin molecules from the simulated saliva also adsorbed to the droplet surfaces (Vingerhoeds et al., 2005).

After incubation in the small intestine phase all the samples had relatively high negative charges, which can be attributed to the presence of anionic species in the various types of particles present (such as undigested lipids, undigested proteins, micelles, vesicles, and calcium salts). These anionic species may have come from the original emulsions (e.g., peptides, free fatty acids, or phospholipids) or from the gastrointestinal fluids (e.g., bile salts and phospholipids). For example, it was previously reported that the presence of free fatty acids decreased the $\zeta$-potential of the lipid droplets in soybean oil-in-water emulsions stabilized by Tween 20 (Waraho, McClements, \& Decker, 2011). There were some significant differences in the electrical characteristics of the particles in the different samples after digestion in the 
small intestinal (Figure 5). In particular, the emulsions that contained long chain triglycerides (corn and fish oil) had more negative charges than those containing MCT or flavor oil. This may have been because the long chain fatty acids generated by digestion of corn and fish oil accumulated at the particle surfaces and contributed to their net charge, whereas the medium chain fatty acids generated by digestion of MCT remained in the aqueous phase (Sek, Boyd, Charman, \& Porter, 2006). It should be noted that the samples will contain a variety of different colloidal particles after digestion in the small intestine, such as undigested lipid droplets, micelles, vesicles, calcium salts, and protein particles. All of these particles could contribute to the overall signal used to calculate the electrophoretic mobility, and therefore the results should be treated with some caution.

\subsection{Influence of oil type on lipid digestion}

In this section, the influence of oil type on the rate and extent of lipid digestion was examined using an automatic titration ("pH-stat") method. The volume of $\mathrm{NaOH}$ $(0.1 \mathrm{M})$ titrated into the samples to maintain a constant $\mathrm{pH}(7.0)$ was measured as a function of digestion time (120 min) during the small intestine stage (Figure 6). The amount of free fatty acids released over time was then calculated from these profiles (Figure 7). As expected, there was little change in the amount of $\mathrm{NaOH}$ that had to be titrated into the emulsions containing flavor oils since these samples did not contain digestible lipids (Figure 6). The small volume of $\mathrm{NaOH}$ that did have to be added to these systems may have been due to digestion of proteins or other substances in the emulsions. Consequently, the orange oil emulsions were used as a control, and the $\mathrm{NaOH}$ volumes measured for this system were subtracted from the measured values for the digestible emulsions before calculation of the FFAs released.

The analysis of the Krill oil samples had to be carried out differently to that of the other samples because they contained a mixture of phospholipids (that may generate one FFA per molecule) and triacylglycerols (that may generate two FFAs per molecule). This was done by assuming that the Krill oil contained $41 \%$ 
phospholipids and 59\% triacylglycerols.

The lipid digestion profiles of the emulsions containing digestible lipids followed fairly similar trends - there was an initial rapid increase in free fatty acids (FFAs), followed by a more gradual increase at longer times, until a relatively constant final value was attained (Figure 7). However, there were some differences in the fatty acid release profiles for emulsions prepared using different oil phases. The rate and extent of lipid digestion was fairly similar for the emulsions containing medium chain triacylglycerols (MCT) or long chain triacylglycerols (LCT). The fatty acid compositions of the different digestible oils used in this study are listed in Table 1. Flavor oils do not contain fatty acids, instead they are comprised of a complex mixture of organic compounds with varying chemical structures and properties, such as monoterpenes, sesquiterpenes, and oxygenates (Rao \& McClements, 2012; Viuda-Martos, Ruiz-Navajas, Fernandez-Lopez, \& Angel Perez-Alvarez, 2009). Table 1 shows that the vegetable and marine oils contained mainly long chain FFAs, whereas the MCT contained mainly medium chain ones. Previous studies have reported that LCT-emulsions are digested slower than MCT-emulsions (Sek, Porter, Kaukonen, \& Charman, 2002; Yang \& McClements, 2013). This effect was attributed to the fact that the digestion products of LCT-emulsions (long chain FFAs) tend to accumulate at the oil-water interface, thereby restricting the access of lipase to the droplet surfaces. Conversely, the digestion products of MCT-emulsions (medium chain FFAs) have a higher affinity for water and therefore rapidly move into the surrounding aqueous phase, thereby making the lipid surfaces easier to access by lipase. However, this effect tends to be more important when there are low levels of calcium present in the system, since calcium ions are known to form insoluble soaps with long chain FFAs that can also remove them from the droplet surfaces (Devraj et al., 2013). The fact that we did not observe a large difference between MCT- and LCT-emulsions suggests that the lipase was able to readily access the emulsified lipids in both types of system. 
The fish oil emulsions contained relatively high amounts of long chain polyunsaturated fatty acids (PUFAs), i.e., DHA and EPA (Table 1). It has previously been reported that triacylglycerols containing PUFAs are hydrolyzed more slowly by porcine pancreatic lipase than those containing monounsaturated fatty acids (MUFAs) (Carlier, Bernard, \& Caselli, 1991; Ikeda et al., 1995; Mu \& Høy, 2004). However, we did not observe an appreciable difference between the digestion of the fish oil and the digestion of the various vegetable oils studied (Figure 7). On the other hand, the rate and extent of lipid digestion was appreciably lower for the emulsions containing krill oil than for the emulsions containing digestible triacylglycerol oils. There are a number of possible reasons for this: (i) the phospholipids may not have been digested by the porcine lipase used in the simulated GIT model in this study; (ii) the structure of the colloidal particles formed in the small intestine may have been resistant to digestion; (iii) there may have already have been some hydrolysis of the lipids in the sample prior to analysis. Indeed, it has previously been reported that krill oil contained $22 \%$ of EPA and $21 \%$ of DHA in the free fatty acid form (Ulven et al., 2011). Krill oil clearly behaves quite differently from other lipids under simulated GIT conditions, and it would be interesting to carry out further studies to examine the origin of these effects and the consequences for developing food-grade delivery systems. Indeed, as mentioned earlier, in vivo studies have also reported appreciable differences in the gastrointestinal fate of free fatty acids depending on whether they are in triacylglycerol or phospholipid forms (Devraj et al., 2013). 
Table 1 Fatty acid composition of selected vegetable oils and marine oils

\begin{tabular}{|c|c|c|c|c|c|c|c|}
\hline $\begin{array}{l}\text { Fatty } \\
\text { acid }\end{array}$ & $\begin{array}{c}\mathrm{MCT}^{\text {(Babayan, }} \\
{ }_{1968)}\end{array}$ & $\begin{array}{c}\text { Corn oil }^{\text {(Ramos, Fernández, Casas, Rodríguez, \& }} \\
\text { Pérez, 2009) }\end{array}$ & $\begin{array}{l}\text { Olive oil }{ }^{\text {(Ramos et al., }} \\
\text { 2009) }\end{array}$ & $\begin{array}{c}\text { Sunflower oil } \\
\text { al., 2009) }\end{array}$ & $\begin{array}{l}\text { Canola oil }{ }^{\text {(Akoh \& }} \\
\text { Moussata, 2001) }\end{array}$ & $\begin{array}{c}\text { Fish oil }^{\text {(Ulven et al., }} \\
\text { 2011) }\end{array}$ & $\begin{array}{l}\text { Krill oil }^{\text {(Ulven et al., }} \\
\text { 2011) }\end{array}$ \\
\hline C8 & 74.4 & - & - & - & - & - & - \\
\hline $\mathrm{C} 10$ & 25.6 & - & - & - & - & - & - \\
\hline C12:0 & - & 0.0 & 0.0 & 0.0 & - & - & - \\
\hline C14:0 & - & 0.0 & 0.0 & 0.0 & - & 3.2 & 7.4 \\
\hline C16:0 & - & 6.5 & 11.6 & 6.2 & 5.0 & 7.8 & 21.8 \\
\hline C18:0 & - & 1.4 & 3.1 & 3.7 & 2.5 & 2.6 & 1.3 \\
\hline C18:1 & - & 65.6 & 75.0 & 25.2 & 61.9 & 6.1 & 18.3 \\
\hline C18:2 & - & 25.2 & 7.8 & 63.1 & 22.0 & 0.8 & 1.8 \\
\hline C18:3 & - & 0.1 & 0.6 & 0.2 & 7.6 & $<0.2$ & 0.2 \\
\hline C20:0 & - & 0.1 & 0.3 & 0.3 & - & 0.6 & $<0.1$ \\
\hline 6 & - & - & - & - & - & 1.5 & 0.5 \\
\hline \multicolumn{8}{|l|}{ C20:4n- } \\
\hline 3 & - & - & - & - & - & $<0.2$ & 0.7 \\
\hline \multicolumn{8}{|l|}{$\mathrm{C} 20: 5 \mathrm{n}-$} \\
\hline 3 & - & - & - & - & - & 27.0 & 19.0 \\
\hline $\mathrm{C} 21: 5 \mathrm{n}-$ & - & - & - & - & - & 1.5 & 0.5 \\
\hline
\end{tabular}




\begin{tabular}{|c|c|c|c|c|c|c|c|}
\hline \multicolumn{8}{|l|}{3} \\
\hline C22:1 & - & 0.1 & 0.0 & 0.1 & - & 2.5 & 0.8 \\
\hline \multicolumn{8}{|c|}{ C22:5n- } \\
\hline 3 & - & - & - & - & - & 4.8 & 0.5 \\
\hline \multicolumn{8}{|c|}{ C22:6n- } \\
\hline 3 & - & - & - & - & - & 24.0 & 10.0 \\
\hline C24:0 & - & 0.1 & 0.5 & 0.2 & - & - & - \\
\hline C24:1 & - & 0.0 & 0.0 & 0.0 & - & $<0.2$ & 0.2 \\
\hline
\end{tabular}




\section{Conclusions}

This study focused on the potential gastrointestinal fate of protein-coated oil droplets prepared using different lipid phases. In general, the particle size of all the samples increased after exposure to simulated GIT conditions, which was attributed to droplet aggregation (flocculation or coalescence) and lipid digestion (formation of micelles, vesicles, and calcium soaps). The electrical properties of the particles in the samples changed throughout the GIT, which was attributed to digestion and displacement of protein molecules from the oil droplet surfaces, as well as to the formation of other types of colloidal particles (such as mixed micelles). As expected, the flavor oils were not digested under simulated GIT conditions because they did not contain triacylglycerols that could be hydrolyzed by lipase. All of the emulsions containing triacylglycerols were rapidly and fully digested under simulated GIT conditions, regardless of their initial FFA compositions. This may be important for functional food applications where a food manufacturer can select a variety of different oil sources and get the same gastrointestinal effect. Conversely, the rate and extent of lipid digestion in emulsions prepared from krill oil was appreciably lower than that of the other oils, which may have been because they contained appreciable amounts of phospholipids and pre-digested triacylglycerols. These results have important implications for the rational design of foods that can control lipid absorption and the bioaccessibility of bioactive components within the GIT.

\section{Acknowledgements}

This material is based upon work supported by the Cooperative State Research, Extension, Education Service, United State Department of Agriculture, Massachusetts Agricultural Experiment Station (Project No. 831) and by the United States Department of Agriculture, NRI Grants (2011-03539 and 2013-03795). 


\section{References}

Akoh, C. C., \& Min, D. B. (2008). Food Lipids: Chemistry, Nutrition, and Biotechnology (Third Edition ed.). Boca Raton, FL: CRC Press.

Akoh, C. C., \& Moussata, C. O. (2001). Characterization and oxidative stability of enzymatically produced fish and canola oil-based structured lipids. Journal of the American Oil Chemists' Society, 78 (1), 25-30.

Babayan, V. K. (1968). Medium-chain triglycerides-their composition, preparation, and application. Journal of the American Oil Chemists' Society, 45 (1), 23-25.

Borel, P. (2003). Factors affecting intestinal absorption of highly lipophilic food microconstituents (fat-soluble vitamins, carotenoids and phytosterols). Clinical Chemistry and Laboratory Medicine, 41 (8), 979-994.

Carlier, H., Bernard, A., \& Caselli, C. (1991). Digestion and absorption of polyunsaturated fatty acids. Reproduction Nutrition Development, 31 (5), 475-500.

Chang, Y., \& McClements, D. J. (2014). Optimization of orange oil nanoemulsion formation by isothermal low-energy methods: influence of the oil phase, surfactant, and temperature. Journal of Agricultural and Food Chemistry, 62 (10), 2306-2312.

Chitchumroonchokchai, C., Schwartz, S. J., \& Failla, M. L. (2004). Assessment of lutein bioavailability from meals and a supplement using simulated digestion and Caco-2 human intestinal cells. Journal of Nutrition, 134 (9), 2280-2286.

Colle, I. J. P., Van Buggenhout, S., Lemmens, L., Van Loey, A. M., \& Hendrickx, M. E. (2012). The type and quantity of lipids present during digestion influence the in vitro bioaccessibility of lycopene from raw tomato pulp. Food Research International, 45 (1), 250-255.

Devraj, R., Williams, H. D., Warren, D. B., Mullertz, A., Porter, C. J. H., \& Pouton, C. W. (2013). In vitro digestion testing of lipid-based delivery systems: Calcium ions combine with fatty acids liberated from triglyceride rich lipid solutions to form soaps and reduce the solubilization capacity of colloidal digestion products. International Journal of Pharmaceutics, 441 (1-2), 323-333.

Farag, R. S., Mahmoud, E. A., \& Basuny, A. M. (2007). Use crude olive leaf juice as a natural antioxidant for the stability of sunflower oil during heating. International Journal of Food Science \& Technology, 42 (1), 107-115.

Gleize, B., Tourniaire, F., Depezay, L., Bott, R., Nowicki, M., Albino, L., Lairon, D., Kesse-Guyot, E., Galan, P., Hercberg, S., \& Borel, P. (2013). Effect of type of TAG fatty acids on lutein and zeaxanthin bioavailability. British Journal of Nutrition, 110 (1), 1-10. 
Hedren, E., Diaz, V., \& Svanberg, U. (2002). Original communications-Estimation of carotenoid accessibility from carrots determined by an in vitro digestion method. European Journal of Clinical Nutrition, 56 (5), 425-430.

Hedrén, E., Mulokozi, G., \& Svanberg, U. (2002). In vitro accessibility of carotenes from green leafy vegetables cooked with sunflower oil or red palm oil. International Journal of Food Sciences and Nutrition, 53 (6), 445-453.

Huo, T., Ferruzzi, M. G., Schwartz, S. J., \& Failla, M. L. (2007). Impact of fatty acyl composition and quantity of triglycerides on bloaccessibility of dietary carotenoids. Journal of Agricultural and Food Chemistry, 55 (22), 8950-8957.

Hur, S. J., Joo, S. T., Lim, B. O., Decker, E. A., \& McClements, J. D. (2011). Impact of salt and lipid type on in vitro digestion of emulsified lipids. Food Chemistry, 126 (4), 1559-1564.

Ikeda, I., Sasaki, E., Yasunami, H., Nomiyama, S., Nakayama, M., Sugano, M., Imaizumi, K., \& Yazawa, K. (1995). Digestion and lymphatic transport of eicosapentaenoic and docosahexaenoic acids given in the form of triacylglycerol, free acid and ethyl ester in rats. Biochimica et Biophysica Acta (BBA)-Lipids and Lipid Metabolism, 1259 (3), 297-304.

Israelachvili, J. N. (2011). Intermolecular and surface forces: revised third edition: Academic press.

Johnson, L. R. (2013). Gastrointestinal physiology: Elsevier Health Sciences.

Kohler, A., Sarkkinen, E., Tapola, N., Niskanen, T., \& Bruheim, I. (2015).

Bioavailability of fatty acids from krill oil, krill meal and fish oil in healthy subjects-a randomized, single-dose, cross-over trial. Lipids in Health and Disease, 14.

Komaiko, J., \& McClements, D. J. (2015). Low-energy formation of edible nanoemulsions by spontaneous emulsification: Factors influencing particle size. Journal of Food Engineering, 146, 122-128.

Li, Y., \& McClements, D. J. (2010). New mathematical model for interpreting $\mathrm{pH}$-stat digestion profiles: Impact of lipid droplet characteristics on in vitro digestibility. Journal of Agricultural and Food Chemistry, 58 (13), 8085-8092.

McClements, D. J., Decker, E. A., \& Park, Y. (2007). Physicochemical and structural aspects of lipid digestion. In Understanding and Controlling the Microstructure of Complex Foods (pp. 483-503). Boco Raton: CRC Press.

McClements, D. J., Decker, E. A., \& Park, Y. (2008). Controlling lipid bioavailability through physicochemical and structural approaches. Critical Reviews in Food Science and Nutrition, 49 (1), 48-67.

McClements, D. J., Henson, L., Popplewell, L. M., Decker, E. A., \& Jun Choi, S. (2012). Inhibition of Ostwald ripening in model beverage emulsions by addition of poorly water soluble triglyceride oils. Journal of Food Science, 77 (1), C33-C38. 
Mu, H., \& Høy, C.-E. (2004). The digestion of dietary triacylglycerols. Progress in Lipid Research, 43 (2), 105-133.

Nidhi, B., \& Baskaran, V. (2011). Influence of Vegetable Oils on Micellization of Lutein in a Simulated Digestion Model. Journal of the American Oil Chemists Society, 88 (3), 367-372.

Porter, C. J. H., Trevaskis, N. L., \& Charman, W. N. (2007). Lipids and lipid-based formulations: optimizing the oral delivery of lipophilic drugs. Nature Reviews Drug Discovery, 6 (3), 231-248.

Qian, C., Decker, E. A., Xiao, H., \& McClements, D. J. (2012). Nanoemulsion delivery systems: Influence of carrier oil on $\beta$-carotene bioaccessibility. Food Chemistry, 135 (3), 1440-1447.

Qiu, C., Zhao, M., Decker, E. A., \& McClements, D. J. (2015). Influence of protein type on oxidation and digestibility of fish oil-in-water emulsions: Gliadin, caseinate, and whey protein. Food Chemistry, 175, 249-257.

Ramos, M. J., Fernández, C. M., Casas, A., Rodríguez, L., \& Pérez, Á. (2009). Influence of fatty acid composition of raw materials on biodiesel properties. Bioresource Technology, 100 (1), 261-268.

Rao, J., Decker, E. A., Xiao, H., \& McClements, D. J. (2013). Nutraceutical nanoemulsions: influence of carrier oil composition (digestible versus indigestible oil) on $\beta$ - carotene bioavailability. Journal of the Science of Food and Agriculture, 93 (13), 3175-3183.

Rao, J., \& McClements, D. J. (2012). Impact of lemon oil composition on formation and stability of model food and beverage emulsions. Food Chemistry, 134 (2), 749-757.

Salvia-Trujillo, L., Qian, C., Martin-Belloso, O., \& McClements, D. J. (2013). Modulating beta-carotene bioaccessibility by controlling oil composition and concentration in edible nanoemulsions. Food Chemistry, 139 (1-4), 878-884.

Salvia-Trujillo, L., Qian, C., Martín-Belloso, O., \& McClements, D. J. (2013). Influence of particle size on lipid digestion and $\beta$-carotene bioaccessibility in emulsions and nanoemulsions. Food Chemistry, 141 (2), 1472-1480.

Sarkar, A., Goh, K. K. T., \& Singh, H. (2009). Colloidal stability and interactions of milk-protein-stabilized emulsions in an artificial saliva. Food Hydrocolloids, 23 (5), 1270-1278.

Schuchardt, J. P., Schneider, I., Meyer, H., Neubronner, J., von Schacky, C., \& Hahn, A. (2011). Incorporation of EPA and DHA into plasma phospholipids in response to different omega-3 fatty acid formulations - a comparative bioavailability study of fish oil vs. krill oil. Lipids in Health and Disease, 10.

Sek, L., Boyd, B. J., Charman, W. N., \& Porter, C. J. H. (2006). Examination of the impact of a range of Pluronic surfactants on the in - vitro solubilisation behaviour and oral bioavailability of lipidic formulations of atovaquone. Journal of Pharmacy and Pharmacology, 58 (6), 809-820. 
Sek, L., Porter, C. J. H., Kaukonen, A. M., \& Charman, W. N. (2002). Evaluation of the in-vitro digestion profiles of long and medium chain glycerides and the phase behaviour of their lipolytic products. Journal of Pharmacy and Pharmacology, 54 (1), 29-41.

Singh, H., Ye, A., \& Horne, D. (2009). Structuring food emulsions in the gastrointestinal tract to modify lipid digestion. Progress in Lipid Research, $48(2), 92-100$.

Tou, J. C., Altman, S. N., Gigliotti, J. C., Benedito, V. A., \& Cordonier, E. L. (2011). Different sources of omega-3 polyunsaturated fatty acids affects apparent digestibility, tissue deposition, and tissue oxidative stability in growing female rats. Lipids in Health and Disease, 10.

Ulven, S. M., Kirkhus, B., Lamglait, A., Basu, S., Elind, E., Haider, T., Berge, K., Vik, H., \& Pedersen, J. I. (2011). Metabolic effects of krill oil are essentially similar to those of fish oil but at lower dose of EPA and DHA, in healthy volunteers. Lipids, 46 (1), 37-46.

Vingerhoeds, M. H., Blijdenstein, T. B. J., Zoet, F. D., \& van Aken, G. A. (2005). Emulsion flocculation induced by saliva and mucin. Food Hydrocolloids, 19 (5), 915-922.

Viuda-Martos, M., Ruiz-Navajas, Y., Fernandez-Lopez, J., \& Angel Perez-Alvarez, J. (2009). Chemical Composition of Mandarin (C-reticulata L), Grapefruit (C-paradisi L.), Lemon (C-limon L.) and Orange (C-sinensis L.) Essential Oils. Journal of Essential Oil Bearing Plants, 12 (2), 236-243.

Waraho, T., McClements, D. J., \& Decker, E. A. (2011). Impact of free fatty acid concentration and structure on lipid oxidation in oil-in-water emulsions. Food Chemistry, 129 (3), 854-859.

Yang, Y., \& McClements, D. J. (2013). Vitamin E bioaccessibility: Influence of carrier oil type on digestion and release of emulsified $\alpha$-tocopherol acetate. Food Chemistry, 141 (1), 473-481.

Zhang, R., Zhang, Z., Zhang, H., Decker, E. A., \& McClements, D. J. (2015). Influence of emulsifier type on gastrointestinal fate of oil-in-water emulsions containing anionic dietary fiber (pectin). Food Hydrocolloids, 45, 175-185.

Zhu, X. Q., Ye, A. Q., Verrier, T., \& Singh, H. (2013). Free fatty acid profiles of emulsified lipids during in vitro digestion with pancreatic lipase. Food Chemistry, 139 (1-4), 398-404. 


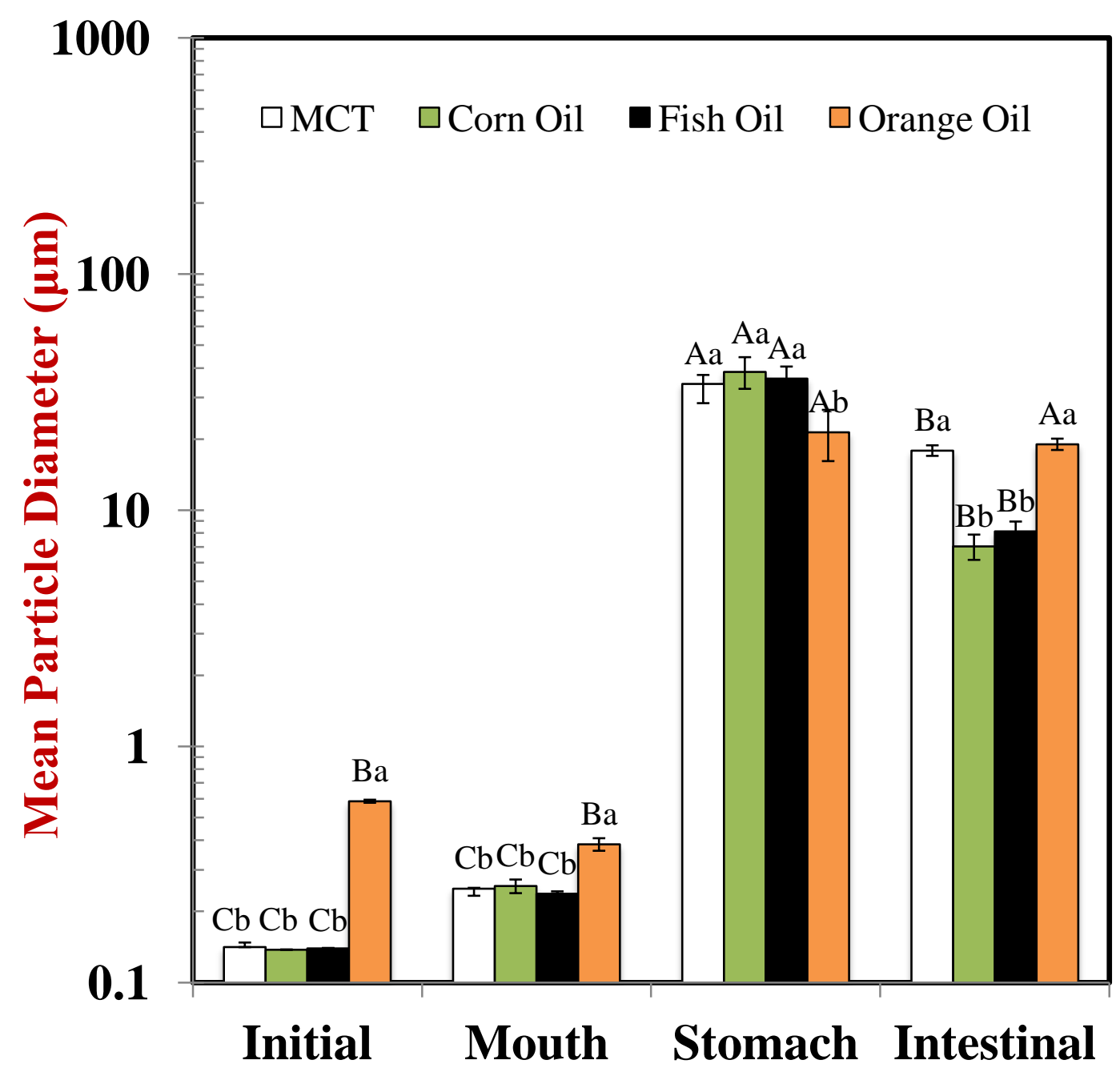

Figure 1. Surface-weighted mean particle diameter of emulsions containing different lipid types: MCT; corn oil; fish oil; and orange oil. A-C values bearing different capital letters compared between different GIT regions are significantly different (Duncan, $\mathrm{p}<0,05)$. a-b values bearing different lowercase letters compared between different lipids type are significantly different (Duncan, $\mathrm{p}<0.05$ ). 
(a) Initial

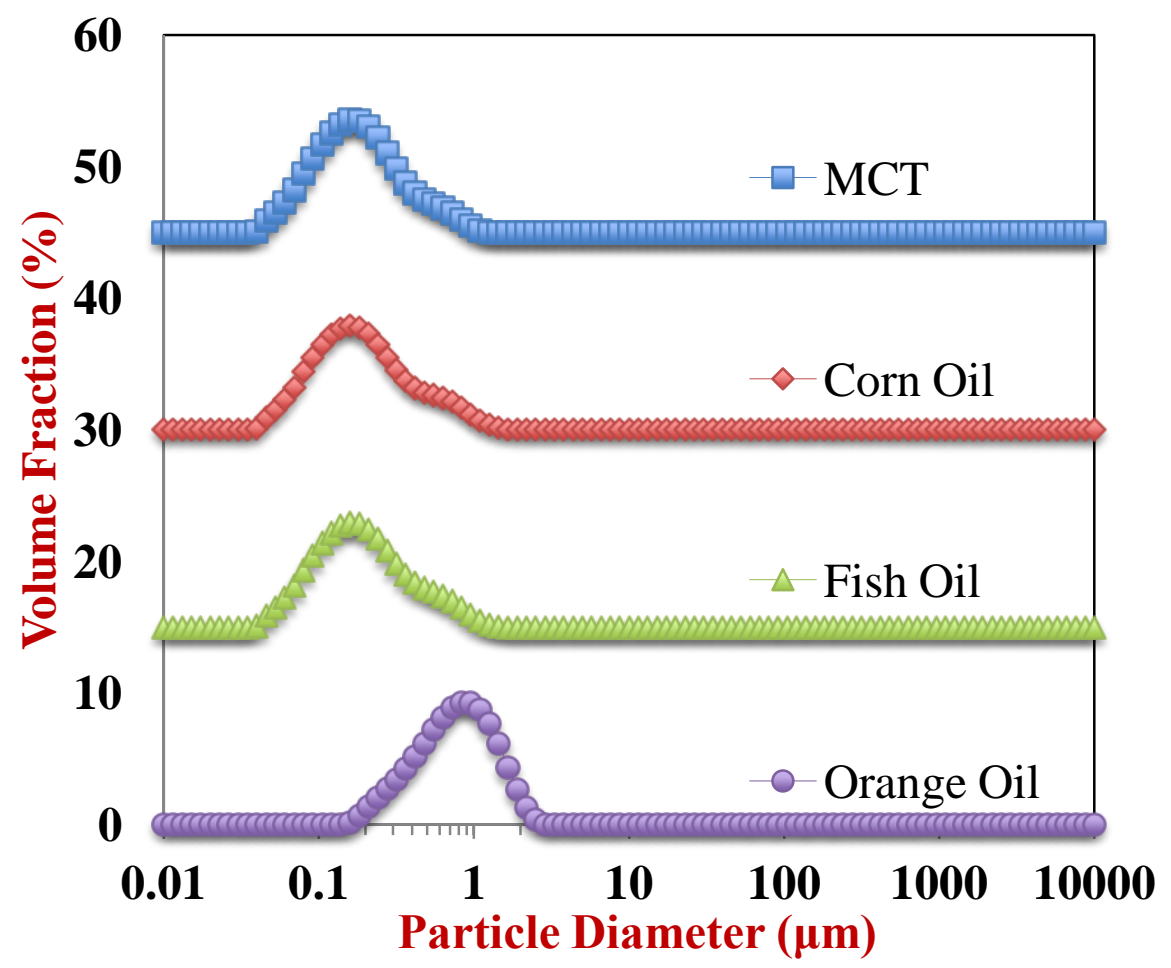

(b) Mouth

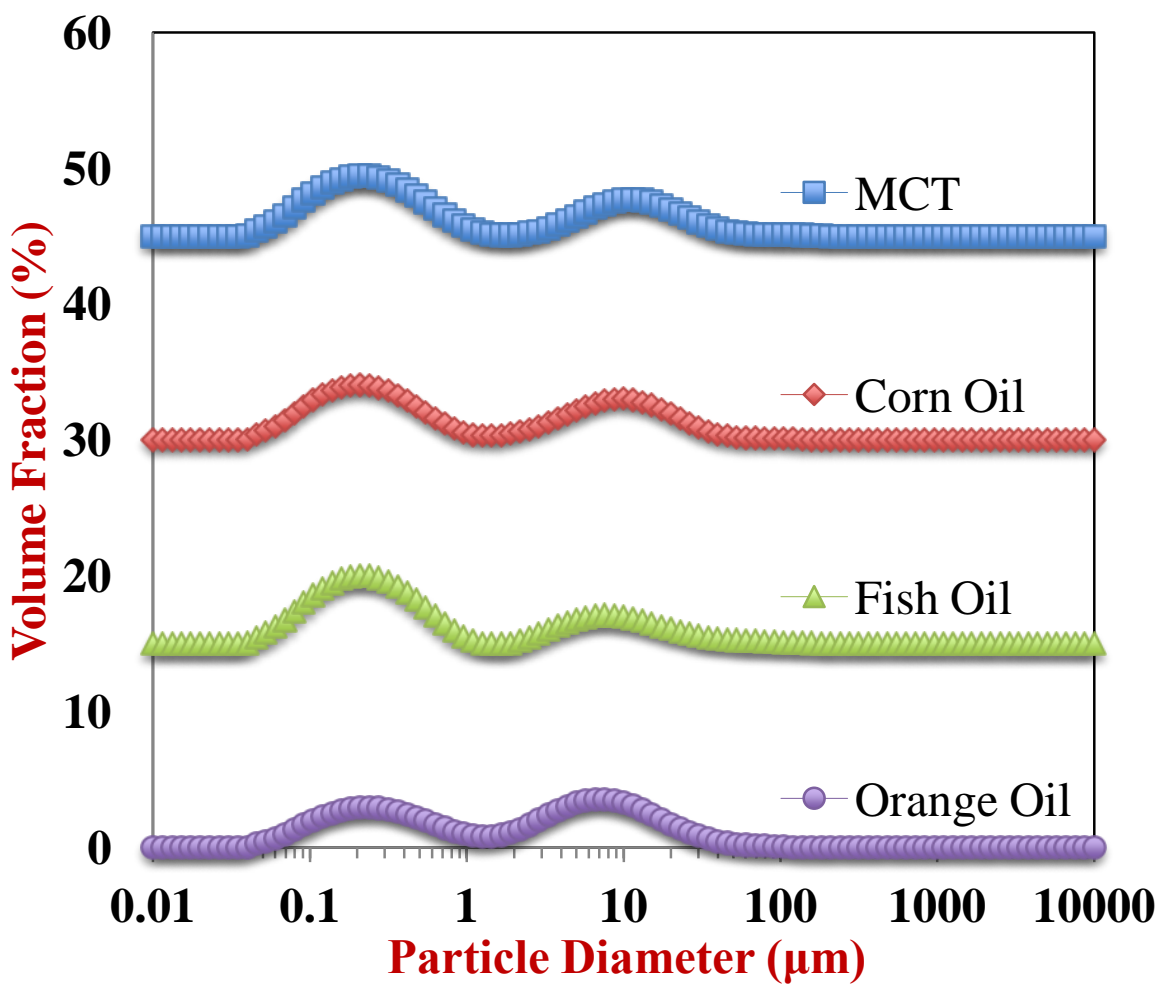


(c) Stomach

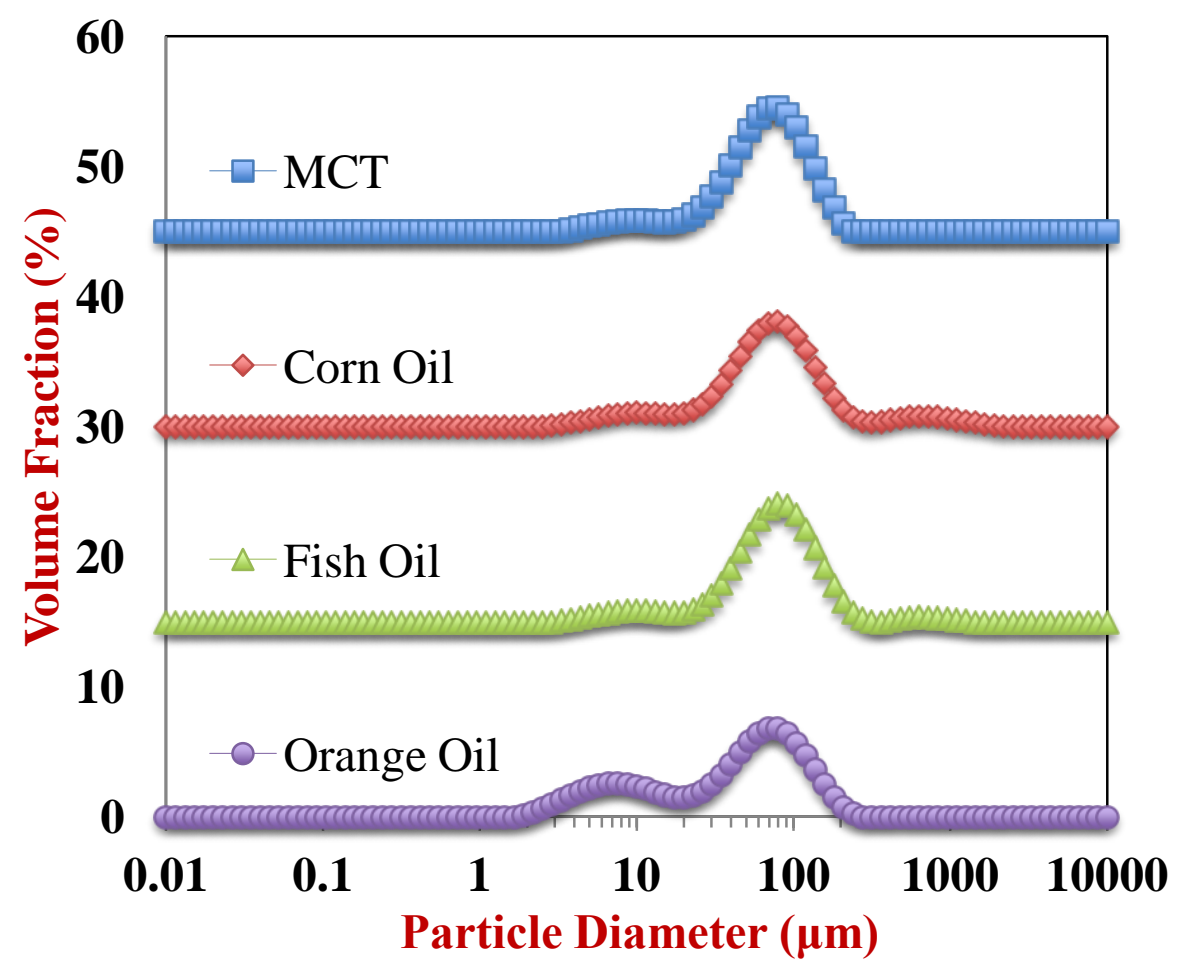

(d) Small Intestine

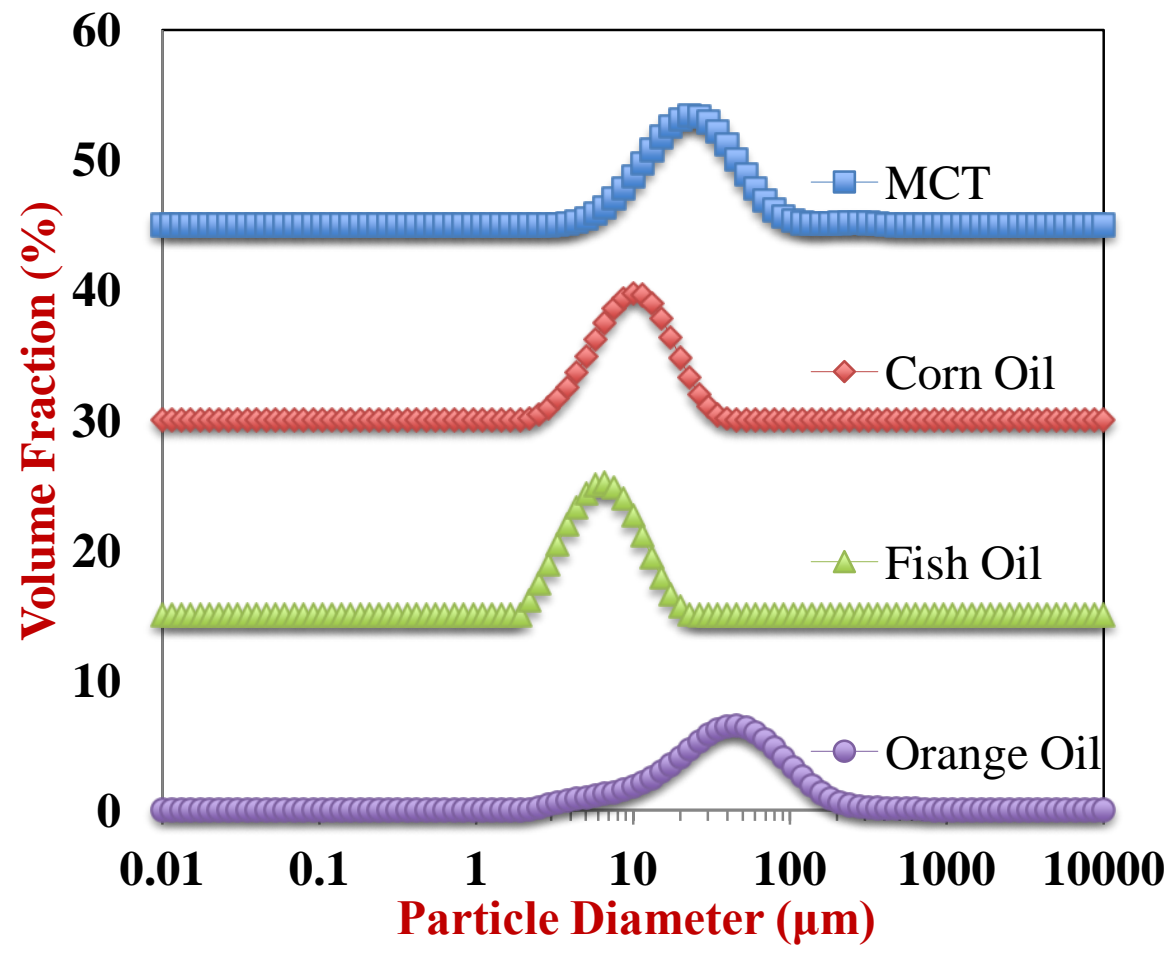


Figure 2. Particle size distribution of emulsions prepared by different lipids type as they passing trough different regions of a simulated GIT: (a) initial; (b) mouth; (c) stomach; and, (d) small intestine. 
(a) MCT

Initial

Mouth

Stomach

Intestine
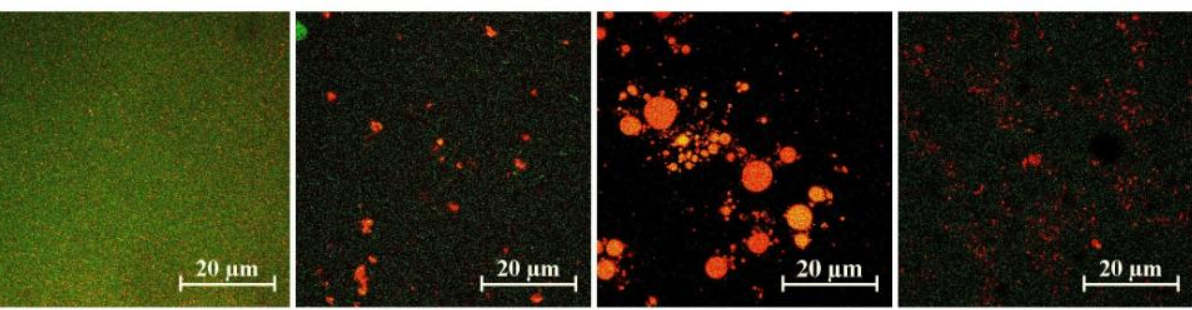

(b) Corn oil
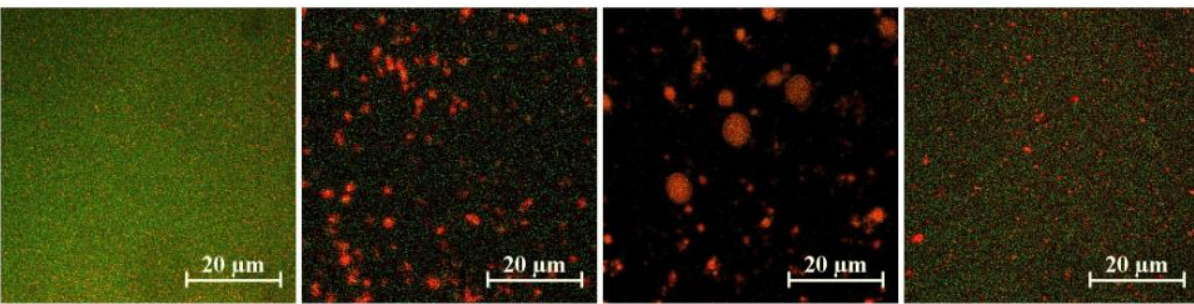

(c) Fish oil
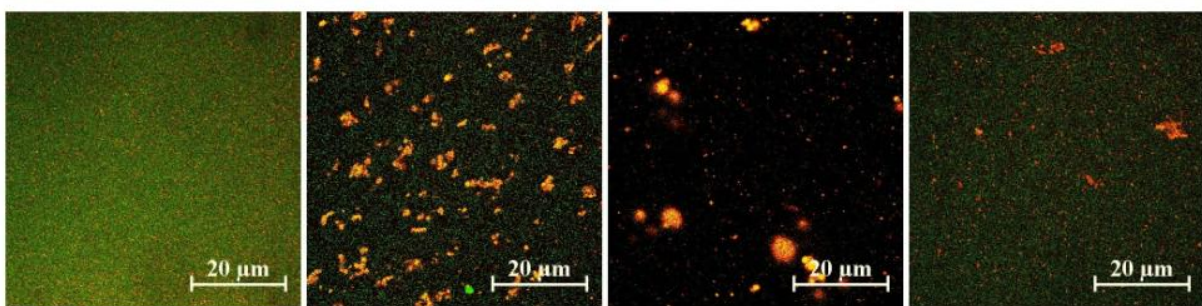

(d) Krill oil
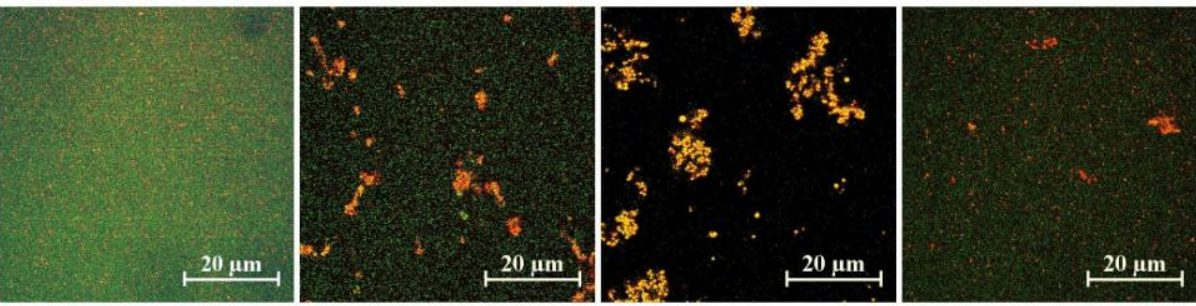

(e) Orange oil
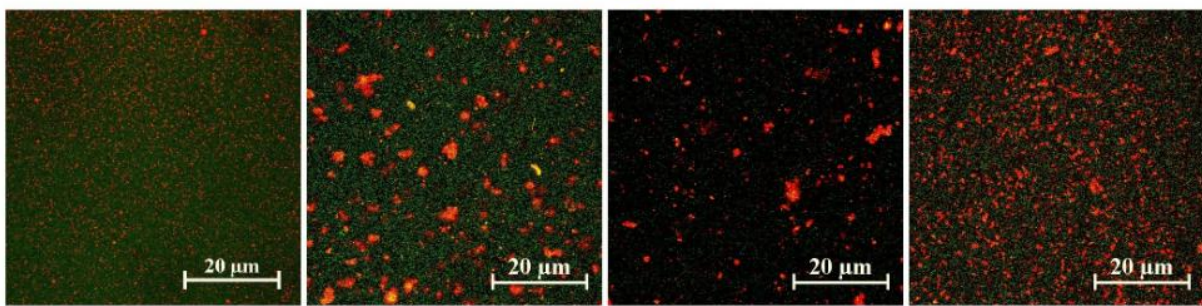

Figure 3. Microstructure of emulsions with different lipids type: (a) MCT; (b) corn oil; (c) fish oil; (d) krill oil; and, (e) orange oil after they were exposed to different regions of a simulated GIT. 

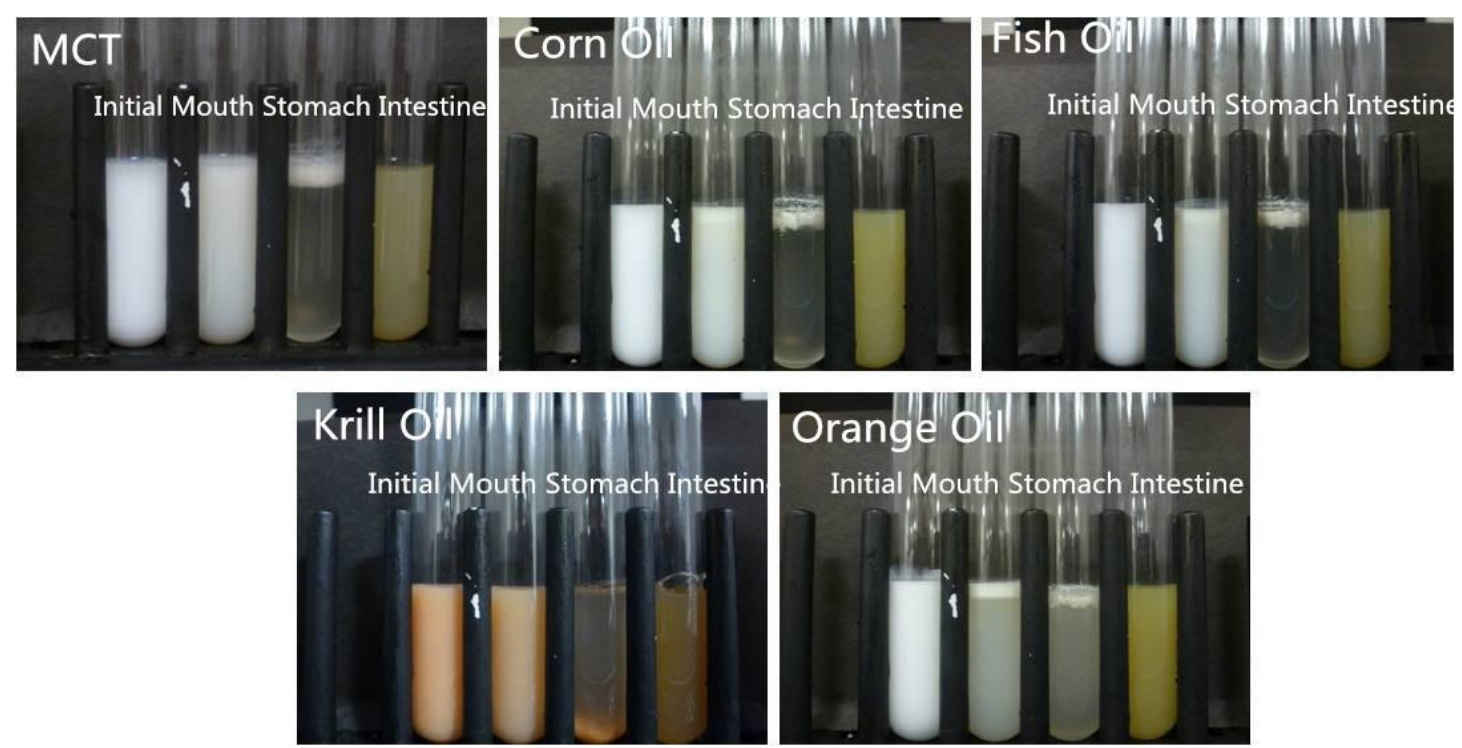

Figure 4. Macroscopic appearance of emulsions with different lipids type [MCT, corn oil, fish oil, krill oil, orange oil] after they were exposed to different regions of a simulated GIT. 


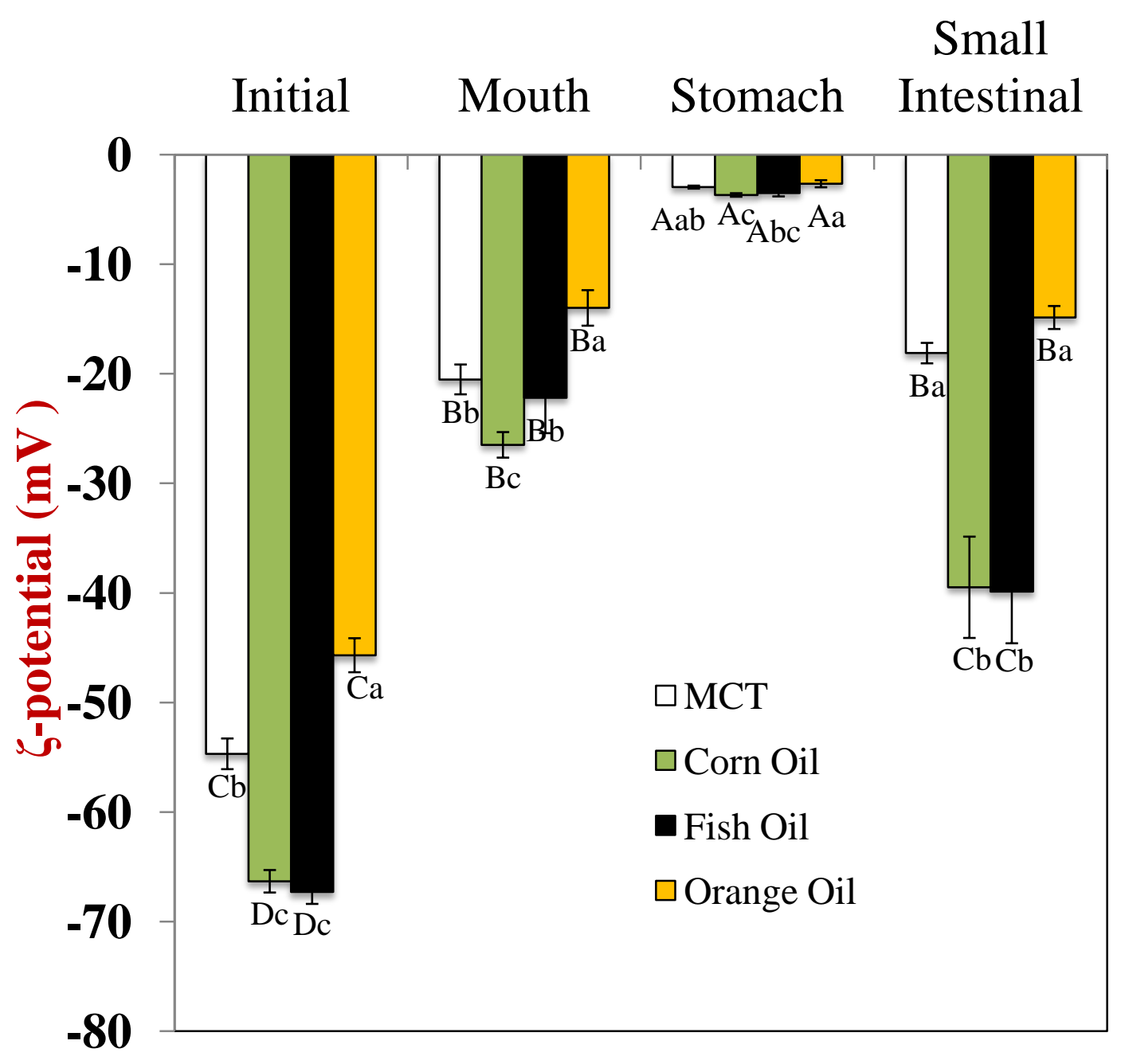

Figure 5. Electrical characteristics ( $\zeta$-potentials) of emulsions containing different lipids type after exposure to different stages of simulated GIT. A-C values bearing different capital letters compared between different GIT regions are significantly different (Duncan, $\mathrm{p}<0,05$ ). a-c values bearing different lowercase letters compared between different lipids type are significantly different (Duncan, $\mathrm{p}<0.05$ ). 


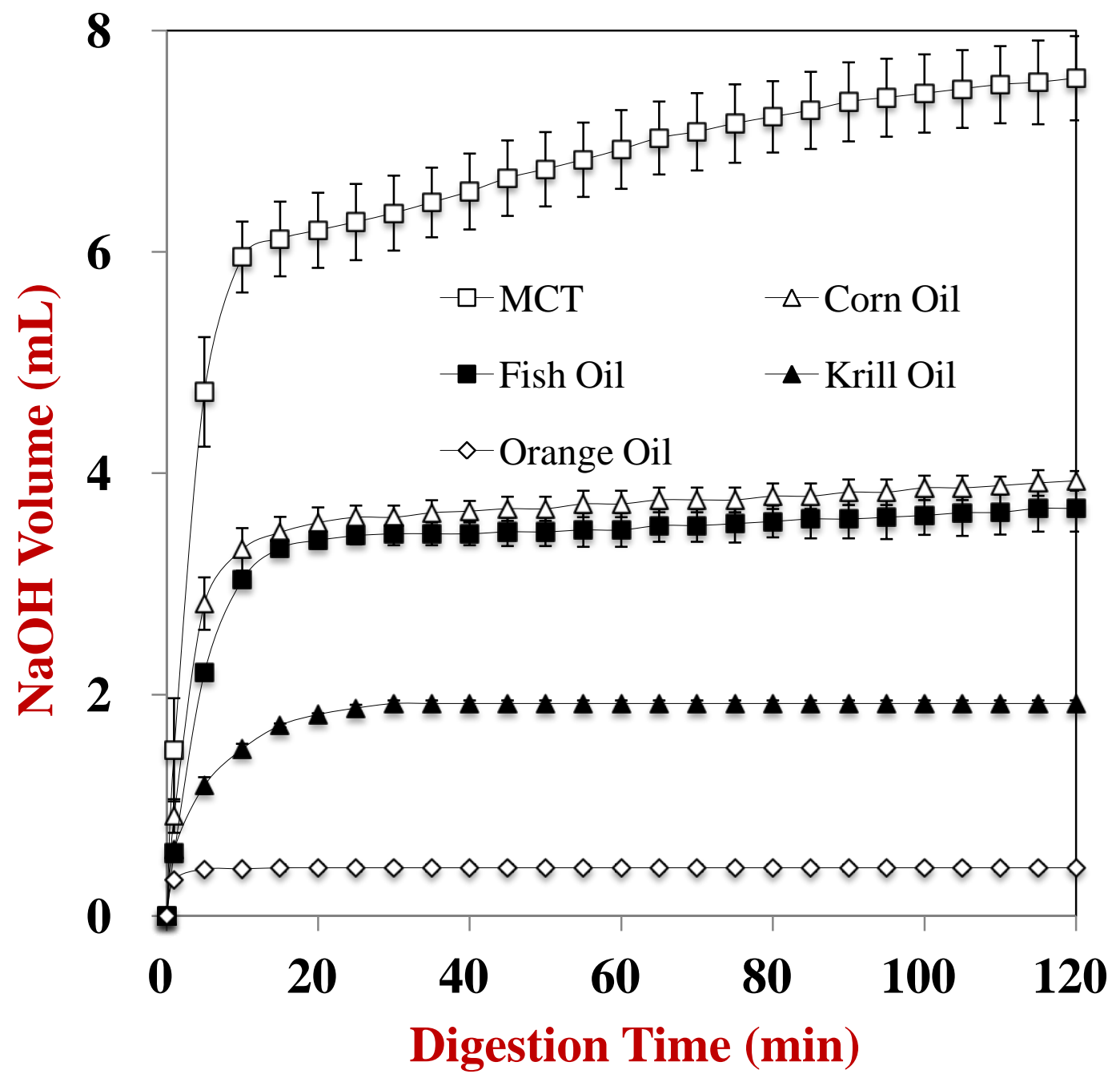

Figure 6. Volume of $\mathrm{NaOH}(0.1 \mathrm{M})$ required to maintain a constant $\mathrm{pH}(7.00)$ in emulsions containing different lipids type as measured using a $\mathrm{pH}$-stat in vitro digestion model. 


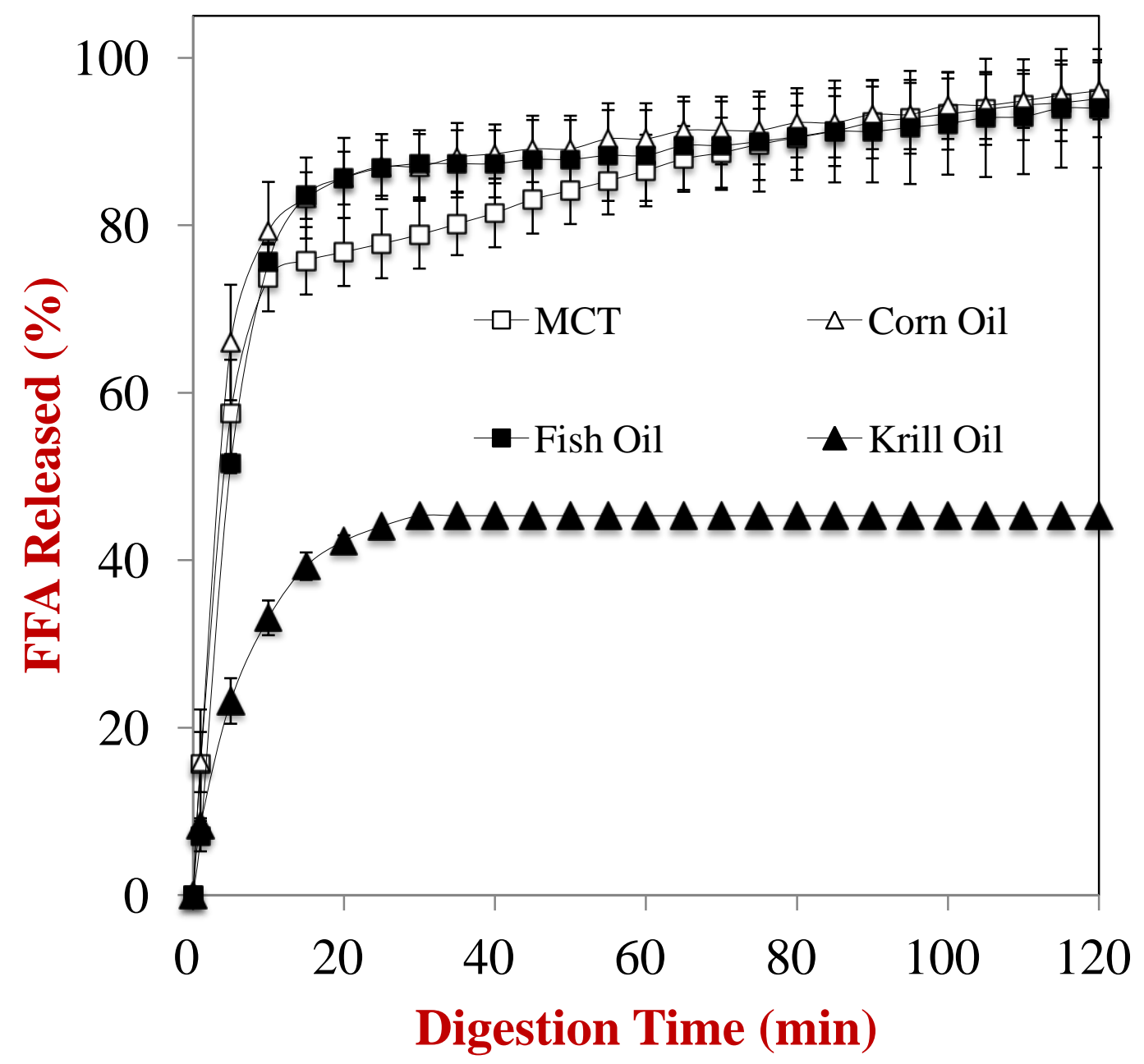

Figure 7. Amount of fatty acids released from emulsions including different lipids type measured in $\mathrm{pH}$-stat in vitro digestion model. 